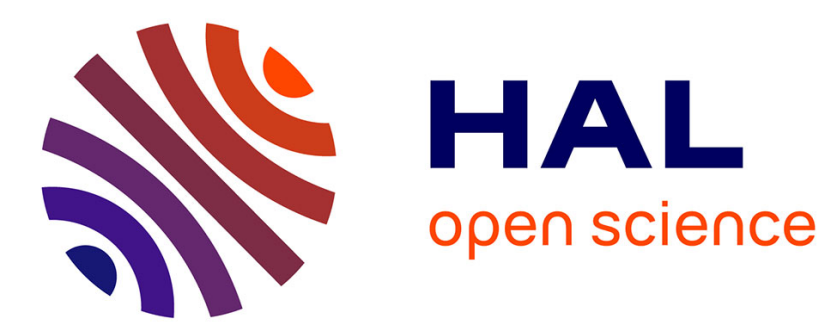

\title{
EXAFS STUDY OF LIQUID AND SOLID GALLIUM, TEMPERATURE AND ANISOTROPY EFFECTS
}

J.P. Badiali, Louis Bosio, Robert Cortès, P. Bondot, G. Loupias, J. Petiau

\section{To cite this version:}

J.P. Badiali, Louis Bosio, Robert Cortès, P. Bondot, G. Loupias, et al.. EXAFS STUDY OF LIQUID AND SOLID GALLIUM, TEMPERATURE AND ANISOTROPY EFFECTS. Journal de Physique Colloques, 1980, 41 (C8), pp.C8-211-C8-213. 10.1051/jphyscol:1980854 . jpa-00220361

\section{HAL Id: jpa-00220361 https://hal.science/jpa-00220361}

Submitted on 1 Jan 1980

HAL is a multi-disciplinary open access archive for the deposit and dissemination of scientific research documents, whether they are published or not. The documents may come from teaching and research institutions in France or abroad, or from public or private research centers.
L'archive ouverte pluridisciplinaire HAL, est destinée au dépôt et à la diffusion de documents scientifiques de niveau recherche, publiés ou non, émanant des établissements d'enseignement et de recherche français ou étrangers, des laboratoires publics ou privés. 


\title{
EXAFS STUDY OF LIQUID AND SOLID EALLIUM. TEMPERATURE AND ANISOTROPY EFFECTS
}

\author{
J.P. Badiali*, L. Bosio*, R, Cortès*, P. Bondot ${ }^{\star \star}$, G. Loupias ${ }^{\star \star}$ and J, Petiau** \\ Laboratoire pour l'Utilisation du Rayonnement Electromagnétique, Bât. 209C, 91405 Orsay, Fronce \\ "Groupe de Recherche $n^{\circ} 4$ du C.N.R.S. "Physique des Liquides et Electrochimie", associé à l'Université \\ Pierre et Marie Curie, 4 place Jussieu, 75230 Paris cedex 05, France \\ "t Laboratoire de Minéralogie et de Cristallogrophie, associé au C.N.R.S. Université Pierre et \\ Marie Curie, 4 place Jussieu, 75230 Paris Cedex 05, France
}

Abstract.- Extended X-ray Absorption Fine Structure (EXAFS) measurements are reported for crystalline solids $\alpha$ and $\beta$-Gallium, and for liquid in the supercooled state. The Comparison of these results to the previous structure knowledge is discussed in terms of both temperature and atomic environment dependence.

\section{INTRODUCTION}

The extended X-ray absorption fine structure is a valuable technique for structural problems and the determination of the local structure around a specific atom is extremely useful in the study of multicomponent solutions or amorphous solids when the partial structure factors are not available. However EXAFS spectrum analysis needs some parameters one can deduce from special experiments of a standard material whose coordination distances are known.

The purpose of this paper is to present the results obtained on gallium and to compare the calculated EXAFS signal with the experimental data. Gallium was chosen for at least two reasons : on the one hand orthorhombic $\alpha-G a$ is a rather suitable candidate for testing anisotropic effect relative to the crystallograpicic orientation and for evaluating the temperature dependence, on the other hand the transferability of the phase shift may be tested on both the allotrope $\beta$-Ga and the liquid.

\section{EXPERIMENTAL}

The experiments were performed at L.U.R.E. on the DCI storage ring of Orsay; the standard setup and EXAFS facilities were used.

The samples consisted of rectangular foils of thickness $35 \mu \mathrm{m}$; the single crystals of $\alpha$-gallium were grown from a seed inserted in liquid squeezed between two plates, the sample orientation being deduced from further $x$-ray diffraction study. Experiments on normal or supercooled liquid and on monoclinic $\beta$-Gallium were carried out on samples consisting on a large number of small droplets settled on a Kapton sheet.
Using a cryostat cooled by liquid helium, the stable $\alpha$-form (melting point $303 \mathrm{~K}$ ) was studied in the temperature range 300 to $20 \mathrm{~K}$, the liquid gallium down to $180 \mathrm{~K}$ where freezing was observed to occur, as seen by differential thermal analysis, and the metastable $\beta-G a$ under its melting point $(257 \mathrm{~K})$ down to $20 \mathrm{~K}$.

\section{EXAFS DATA AND RESULTS}

In a material composed of one kind of atom, the amplitude $x(k)$ of the fine structure oscillations occuring on the absorption coefficient as a function of energy $E$ above the $K$-edge $E_{0}$, can be described by the expression [1]:

$x(k)=-\frac{f(k, \pi)}{k} \int_{0}^{\infty} \frac{D(R)}{R^{2}} \exp \left[\frac{-2 R}{\lambda(k)}\right] \sin [2 k R+\alpha(k)] d R$ $k=2 m\left(E-E_{0}\right)^{1 / 2}$ is the photoelectron wave vector, $f(k, \pi)$ the back-scattering amplitude, $D(R)$ is the pair distribution function, $\lambda(k)$ the electron mean free path and $\alpha(k)$ the total phase shift.

In a crystal it is generally assumed that the pair distribution of atoms surrounding the absorbing aton is gaussian in form (with a mean square relative displacement $\sigma^{2}$ of the atom) and can be expressed as a sum of shells of $\mathrm{Ni}$ atoms at the average distance $R_{i}$ so that equ. 1 becomes :

$$
\begin{aligned}
x(k)= & -3 \frac{f(k, \pi)}{k} \sum_{i}\left(\vec{e}, \vec{R}_{i}\right)^{2} \frac{N_{i}}{R_{i}^{2}} \exp \left(-2 \sigma_{i}^{2} k^{2}\right) \\
& \exp \left[\frac{-2 R_{i}}{\lambda(k)}\right] \sin \left[2 R_{i} k+\alpha(k)\right]
\end{aligned}
$$

This expression also includes the polarization dependence, $\vec{e}$ being the polarization vector of the $X$-ray beam.

In most previous works structural informations have been determined by Fourier transformation. But in order to avoid problems in determining the 
window function to isolate the successive shells of neighbours and since the structures under investigation are known in our case, we choose to compare the measured values to the computed EXAFS signal, in the $k$-space.

Experiments were performed at $20 \mathrm{~K}$ on $\alpha-\mathrm{Ga}$ single crystals whose orientations relative to the polarization vector $\vec{e}$ are such that the four first coordination shells differently contribute to the EXAFS signal : the two spectra shown in fig. la and $1 \mathrm{~b}$ exhibit significant difference over the whole range of $k$; these measurements clearly confirm previous results $[2,3,4]$ relative

to EXAFS orientation dependence. In fig. 1 are also plotted the theoretical curves computed from equ. 2 ; the fitted phase shift expressed by : $-3.8 \times 10^{-4} k^{3}+2.8 \times 10^{-2} k^{2}-0.99 k+9.55$ is very comparable to that deduced from TEO and LEE calculation [5], the main incertitude arising from the exact threshold energy determination. The general agreement concerning both oscillations and amplitudes, between experiment and theory is reasonably good over the range $3.3-13 \AA^{-1}$ since $\sigma$ and $\lambda(k)$ have been keeped constant and $f(\pi, k)$ is the calculated value [5].

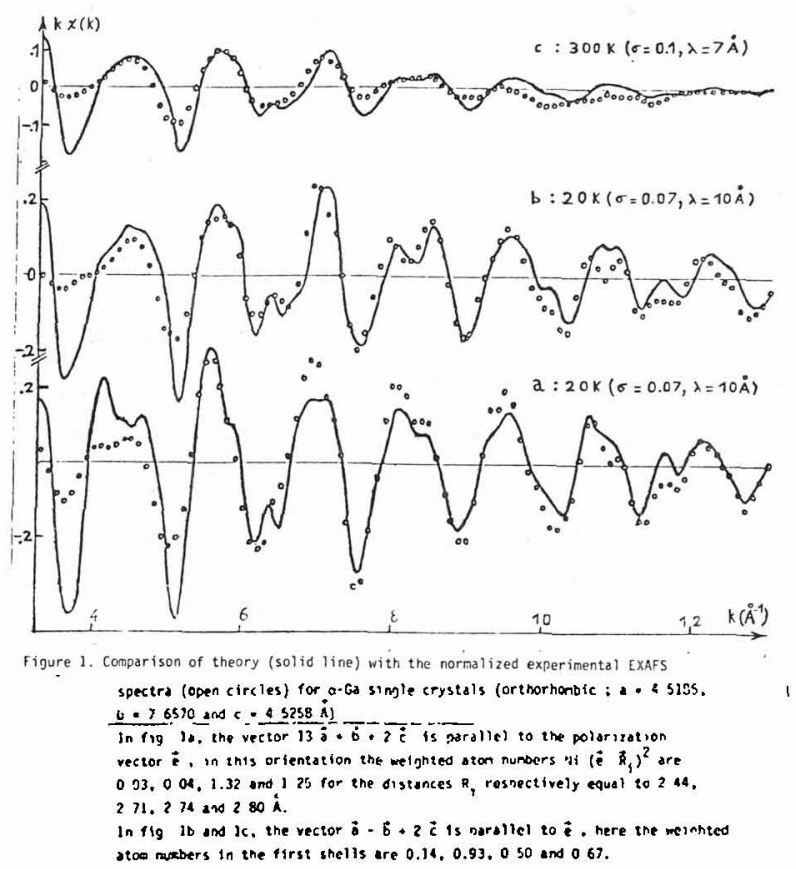

In employing EXAFS for unknown structure determination, it is generally assumed that $f(\pi, k)$ and $\alpha(k)$ of the absorbing atom are independent of the atomic environment. Gallium offers the opportunity to test this basic assumption since at least two different crystalline structures may be available at very low temperature ; (i) the orthorhombic $\alpha$-form, just studied above, where each atom has a first neighbour at $2.44 \AA$, (ii) the metastable monoclinic $\beta$-form, where each atom has two nearest neighbours at $2.68 \AA$.

The results obtained on a polycrystaliine $B$-Ga sample at $20 \mathrm{~K}$ are plotted in fig. $2 \mathrm{a}$; the theoretical curve, calculated with the same parameters as those used for $\alpha-G a$, show that the atomic environment has little importance about the transferability of the phase shift.

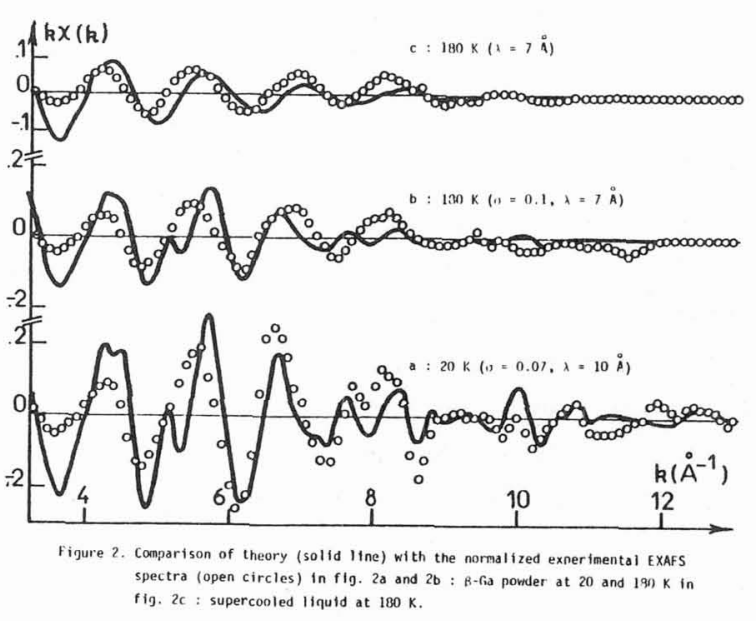

This is true at very low temperature but partly fails when temperature is raised; if no significant change in the phase shift can be seen in $\alpha-G a$ at $300 \mathrm{~K}$ as illustrated in fig. $1 \mathrm{c}$, a change in the phase function is obvious in $B-G a$ at $180 \mathrm{~K}$ (fig. 2b). As reported by EISENBERGER and BROWN [1], this behaviour may be comes from the fact that the gaussian pair distribution function assumed to establish equ. 2 is an oversimplication and a more realistic model has to be used in the $B-G a$ where thermal expansion and anharmonic effects are at least twice higher than in $\alpha-G a$ [6].

Another confirmation of this point of view is provided by experiments on liquid gallium (fig.2c): EXAFS spectrum concerning highly supercooled liquid at $180 \mathrm{~K}$ has less details than crystalline B-Ga at the same temperature (fig. 2b) because of lack of Tong range order but the major maxima and zero positions of both coincide (experimental curves, open circles); we are not surprised since $X$-ray diffraction studies had already shown a similarity between liquid and B-structure. But it is of particular 
importance to note that in liquid state the theoretical curve (fig. 2c) calculated from equ. 1 by using the diffraction data and the phase shift previously deduced, matches well the observed curve actually, no assumption has been made about shell shape.

\section{CONCLUSION}

Extended $X$-ray absorption fine structure spectroscopy has been applied to the study of liquid and solid gallium; the well known structures of this monoatomic system can serve to test the applicability of this technique as function of the atomic environment, orientation and temperature. He conclude that EXAFS results agree quite well, especially at very low temperature, with information provided by conventional $X$-ray diffraction. For this study, experimental and calculated results were compared in the k-space ; but it is to be feared that in such complex structures, the overiapping shells of neighbours will encounter severe problems to extract the structural information by using Fourier transform from $k$-space to $R$-space.

\section{ACKNOHLEDGMENTS}

The authors are grateful for beam time and for technical support at L.U.R.E. ; they also thank the staff of the Laboratoire de l'Accélérateur Linéaire for dedicated runs at the DCI storage ring.

\section{REFERENCES}

[1] EISENBERGER, P., BROWN, G. S., Solid State Communications 29 (1979) 481.

[2] BENI, G., PLATZMAN, P. M., phys. Rev. B14 (1976) 1514.

[3] WEBER, W. M., Phys. Stat. Soz. (b) 91 (1979) 667.

[4] RABE, P., TOLKIEHN, G., WERNER, A., J. Phys.C: Solid State Phys. 13 (1980) 1857.

[5] TEO, B. K., LEE, P. A., J. Am. Chem. Soc. 101 (1979) 2815.

[6] CORTES, R., Thèse, Paris 1974. 